\title{
Diagnosis of Fetal Anomalies in Developing Country: Experiences in Indonesia
}

\author{
Azen Salim ${ }^{1}$, Gulardi Hanifa Wiknjosastro', I Gede Putu Surya ${ }^{4}$, Bambang Karsono ${ }^{1}$, I Made Kornia Karkata ${ }^{4}$, \\ Noroyono Wibowo', Wiku Andonotopo ${ }^{2,3}$, I Nyoman Hariyasa Sanjaya ${ }^{4}$ \\ ${ }^{1}$ Department of Obstetrics and Gynecology, Fetomaternal Division, Medical School, Indonesian University, Cipto Mangunkusumo \\ Hospital, Jakarta, Indonesia \\ ${ }^{2}$ Departments of Obstetrics and Gynecology, Medical School, University of Zagreb, Sveti Duh General Hospital, Zagreb, \\ Croatia \\ ${ }^{3}$ Department of Health, Ministry of Health, Republic of Indonesia, Jakarta, Indonesia \\ ${ }^{4}$ Department of Obstetrics and Gynecology, Fetomaternal Division, Medical School, Udayana University, Sanglah Hospital, \\ Denpasar, Bali, Indonesia
}

Correspondence: Wiku Andonotopo, MD, PhD, Department of Obstetrics and Gynecology, Sveti Duh General Hospital, Medical School, University of Zagreb, Sveti Duh 64, 10000 Zagreb, Croatia.

Tel: +38591 8895288. Fax: + 38513745534 E-mail: drwiku@yahoo.com

\begin{abstract}
Although three-dimensional ultrasound (3DUS) has been available for more than 10 years in Indonesia, there was no publishing article from our region which systematically evaluates our experiences in this most recent ultrasound technologies and its application to obstetric. 3DUS is revolving into a technology with various range of applications in numerous fields because it helps overcome some of the key limitations related to two-dimensional imaging. It is through this review that we attempt to develop a continuous line of understanding the current diagnostic benefits of 3D and 4DUS in diagnosis of fetal abnormalities and consider the utility and role of this type of imaging in the routine clinical practice.
\end{abstract}

Key words: Three-dimensional; four-dimensional, ultrasound; obstetrics; fetal abnormalities.

\section{INTRODUCTION}

Ultrasound has been used as imaging tool in limited medical practice for more than 20 years in Indonesia, which has proved helpful for the diagnosis of fetal abnormalities. The observation and description of fetal morphology in early pregnancy has become feasible. Consequently, fetal anomalies are able to be diagnosed at an earlier stage with more precise observation.

Although 3DUS has been available for about 10 years in our region, it was through the development of the most recent computer technologies and its adjustment to ultrasound systems, that 3DUS has become able to attain the high level of sensitivity and performance compulsory to be considered seriously in clinical practice. 3DUS is revolving into a technology with various range of applications in numerous fields because it helps to overcome some of the key limitations related to twodimensional (2DUS) imaging. ${ }^{1-10}$
It is considered that the supplemental use of 3D multiplanar and surface image information to the conventional 2DUS contributes to the diagnosis of fetal anomalies in the first trimester of pregnancy. This article reviews the diagnosis of fetal abnormalities with particular consideration of the contribution of 3DUS, showing our own cases from several centers in Indonesia.

\section{USE OF 3DUS FOR DIAGNOSING FETAL ABNORMALITIES}

The technique of measuring nuchal translucency between the 11th and 14th weeks of pregnancy has allowed a high rate of detection of chromosomal abnormalities. ${ }^{1-3,10-15}$ In a series of 120 pregnancies, it has been possible to obtain the midsagittal section and measure nuchal translucency in all cases studied using 3D transvaginal sonography (Fig. 1). ${ }^{9}$ The ability of 3D ultrasound to distinguish between the nuchal region and the amnion will aid greatly in this very important screening examination. ${ }^{9}$ Transabdominal scanning is often a more reliable method for obtaining measurement of nuchal thickness because of the lack of flexibility of movement of the transvaginal probe in the vaginal vault. We will review here examples of some fetal abnormalities in which 3DUS is helpful as powerful diagnostic tool.

\section{Non-immune Hydrops Fetalis}

Non-immune hydrops fetalis is thought to be a common symptom of fetal disease at any stage, even in the first trimester of pregnancy. ${ }^{1-3,10}$ Generalized skin edema is believed to be the 


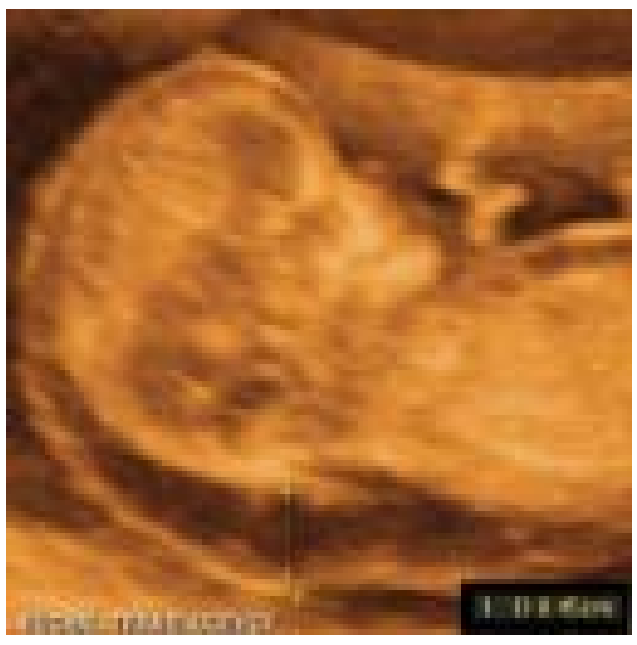

Fig. 1: 3DUS technique of measuring nuchal translucency during first trimester. This technique has allowed a high rate of detection of chromosomal abnormalities first feature of fetal hydrops, and when increased nuchal thickness is included in its signs (Figs 2A to C), abnormality of the fetal neck was reported to be diagnosed as early as 9th week of gestation. ${ }^{16}$ Non-immune hydrops cases diagnosed at an early gestational age have a higher incidence of abnormal karyotype and a higher perinatal mortality rate. ${ }^{17}$

\section{Cystic Hygroma}

Cystic hygroma is defined as fluid-filled sacculations of the lateral neck and nuchal region that result from lymphatic dysplasia. It is often associated with generalized skin edema and it is always septated and bilateral (Figs 3A and B). Cullen and coworkers reported that cystic hygroma was the most common anomaly in the first trimester. ${ }^{1-3,10,18}$ It is considered that to delineate a cystic hygroma with septation, multiplanar display of 3D ultrasound is more useful than conventional 2D ultrasound.

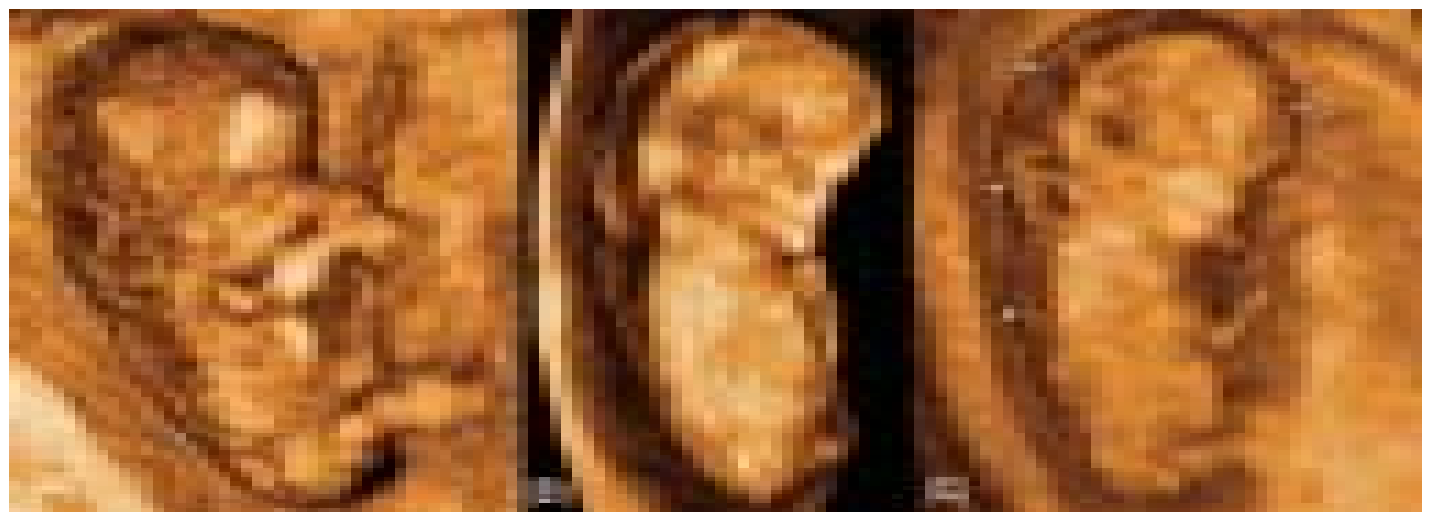

Figs 2A to C: 3D surface imaging of non-immuned hydrops fetalis at 10 weeks of gestation. Note the thickness of the nuchal translucency can be clearly depicted by 3DUS (arrow)
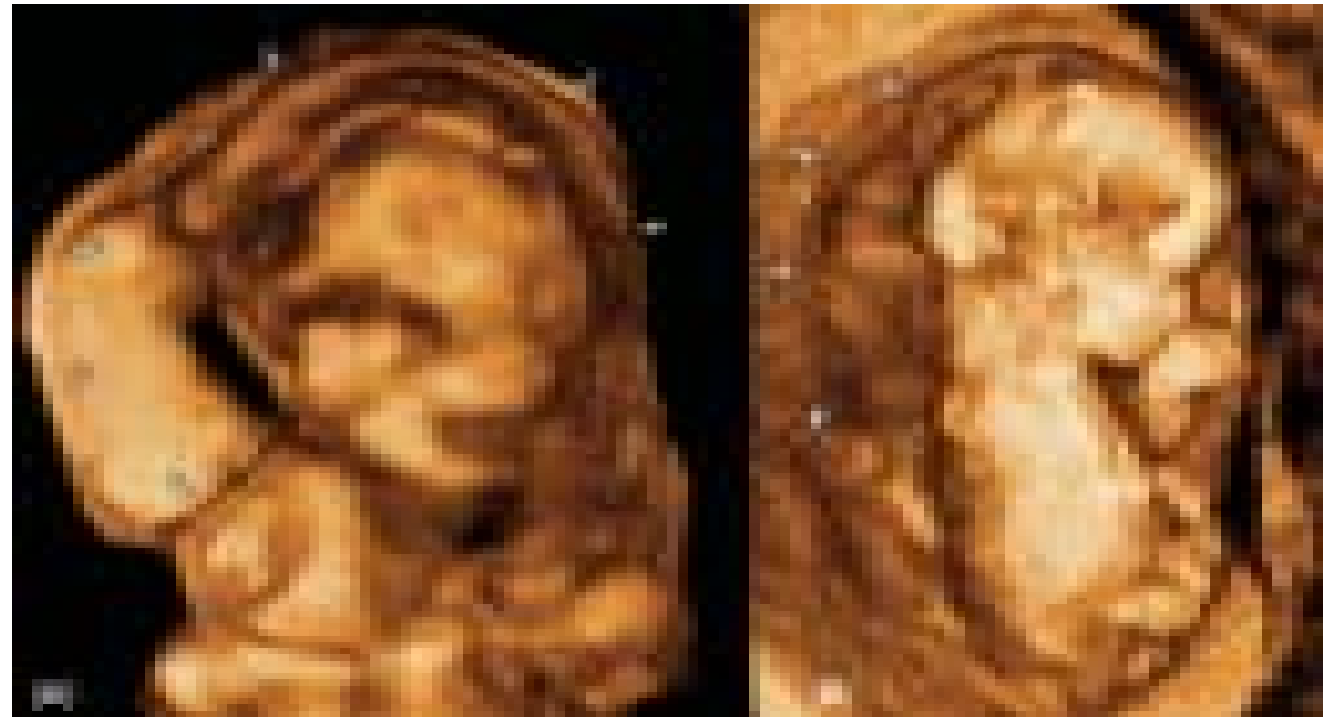

Figs $3 A$ and $B: 3 D$ surface imaging of large cystic hygroma at 11 weeks of gestation (arrow) 


\section{Acardiac Twins}

Acardiac malformation, also known as twin reversed arterial perfusion (TRAP) sequence, is a unique complication of monochorionic twinning. It is characterized by lack of heart development associated with a spectrum of malformations and reduction anomalies in one of the twins, which is perfused in a paradoxical retrograde fashion by a structurally normal 'pump' twin through a single artery-to-artery anatomosis. ${ }^{19}$ Acardiac twins can be diagnosed antenatally on ultrasound by the absence of identifiable cardiac pulsation and poor definition of the head, trunk and upper extremities, deformed lower extremities which may show some movements, and usually marked tissue edema and abnormal cystic areas in the upper part of the body of the affected twin (Figs 4 and 5). ${ }^{19}$

\section{Complete Hydatidiform Mole and Coexisting Healthy Twin}

Complete hydatidiform mole and coexisting healthy twin (CMHT) is a rare phenomenon resulted from the independent fertilization of two eggs, while the complete mole had a paternal origin with diploid karyotype. The molar tissue could be diagnosed by ultrasound examinations as a distinctly separated tissue from the fetus and the placenta (Figs 6A and B). In this case, karyotyping was not performed during the first trimester, because the pregnancy and the molar structures were misinterpreted as a hematoma. ${ }^{20}$ Several clinical scenarios should be considered when ultrasound findings have suspected in molar pregnancy. Jauniaux and colleagues stated that in the case of partial molar pregnancy, ultrasound findings demonstrated a fetus affected with major malformations and

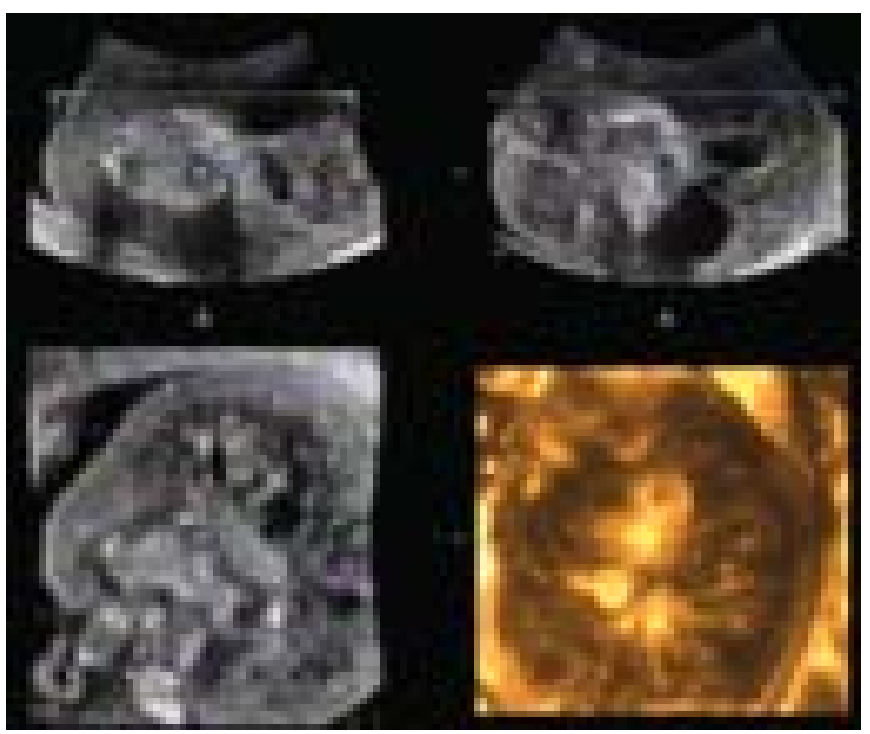

Fig. 4: Visualization of 3D multiplanar imaging of acardiac twins. Note the bizarre structure of the monstrous affected twins can be clearly depicted by 3DUS

complicated with severe and early asymmetrical growth restriction. ${ }^{21}$ In other case like placental mesenchymal dysplasia, cystic appearance of the placenta on ultrasound imitated the molar pregnancy. However, the histopathologic examination confirms distinctive non-molar features.

\section{Hydrocephalus}

Hydrocephalus is characterized by an abnormal accumulation of cerebrospinal fluid within the ventricular system. Diagnosis of ventricular abnormalities should be known from which

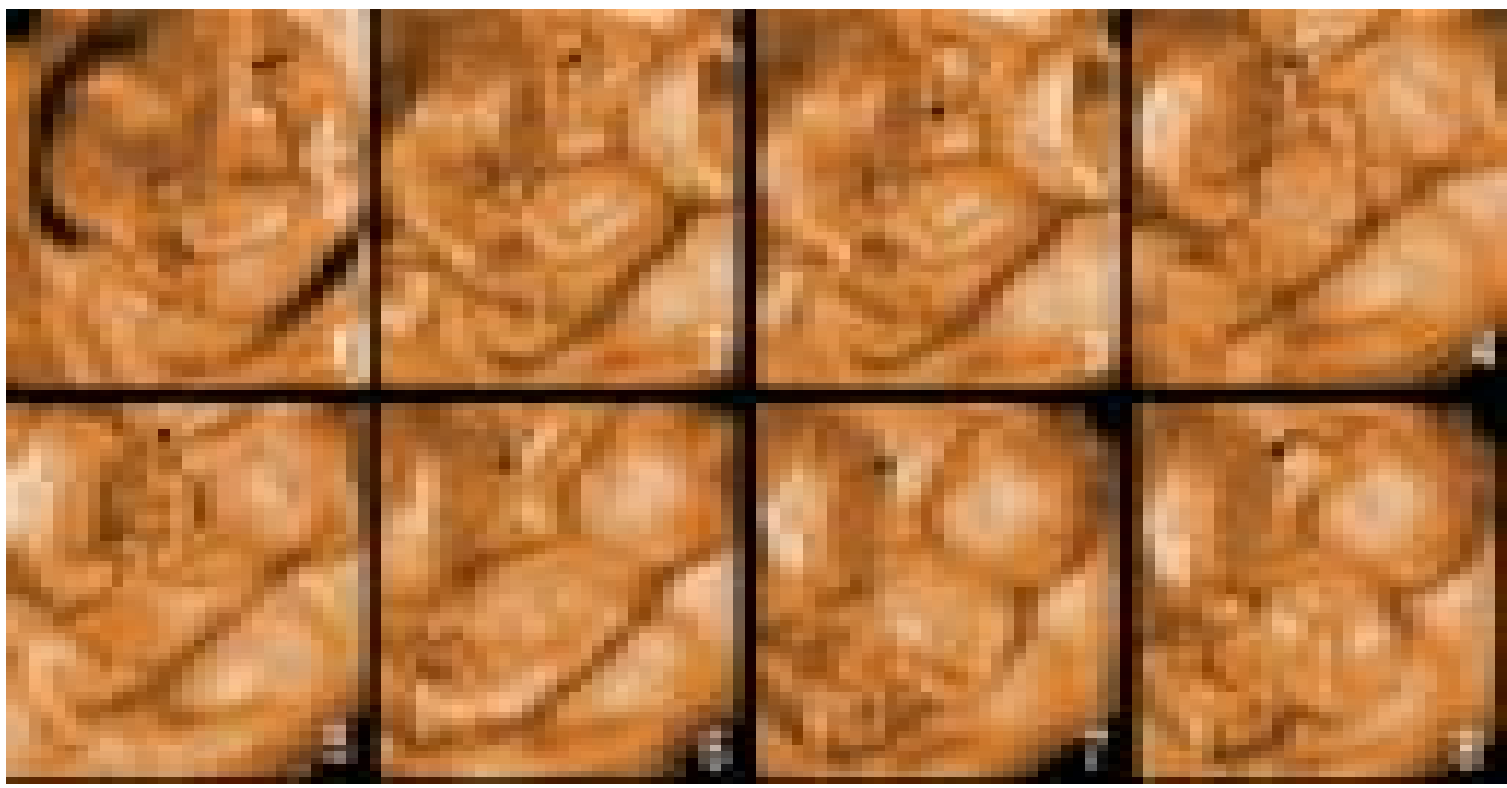

Fig. 5: Visualization of fetal movements by 4D sonographic in pregnancy complicated by acardiac twins (arrow) 


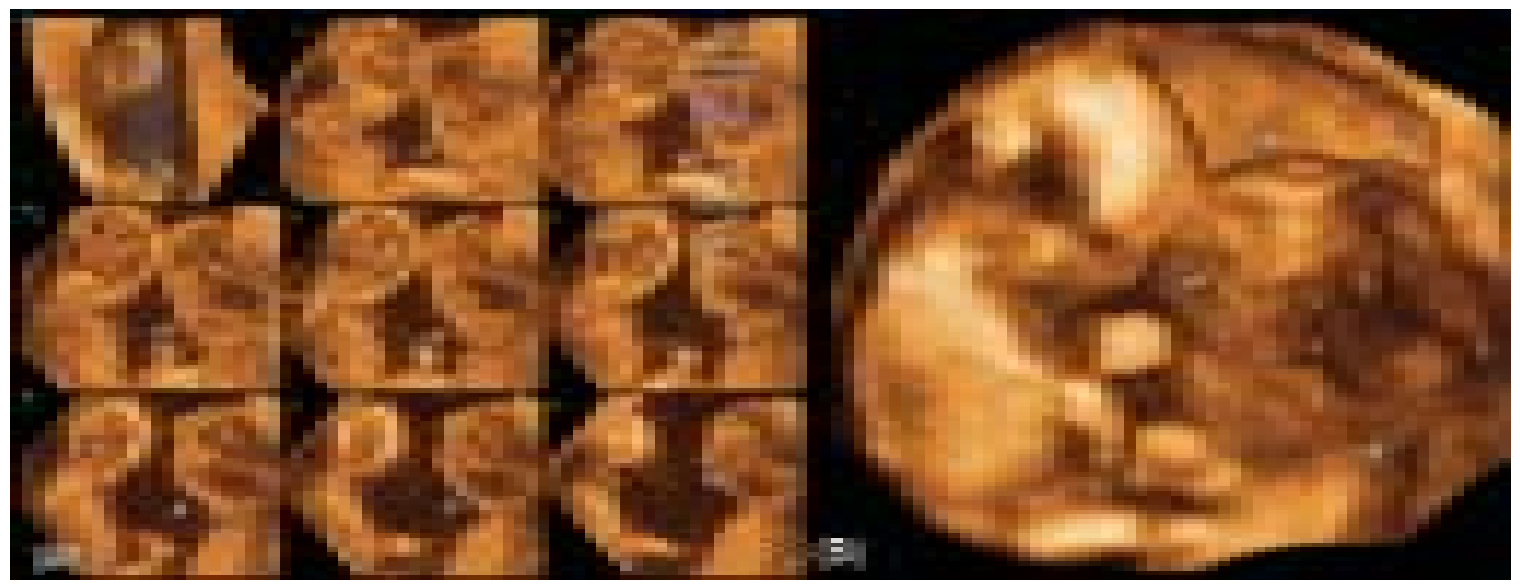

Figs 6A and B: (A) Tomographic ultrasound imaging of the pregnancy complicated by complete molar and coexisting twins; (B) 3D surface imaging of molar structure and fetus (arrow)

gestational age a particular structural abnormality can be depicted. ${ }^{22}$ In the case of hydrocephalus, ventriculomegaly develops after the 14th week of gestation. For many years, it was thought that hydrocephalus could not be diagnosed before 22 to 24 gestational weeks, as until the lateral ventricles are normally large in relation to the width of the cerebral hemispheres. In most cases, hydrocephalus is thought to be due to an obstruction of the aqueduct of Sylvius, which prevents the passage of the cerebrospinal fluid from the lateral and third ventricles into the fourth ventricle, resulting in ventriculomegaly and increased intracranial pressure (Figs 7A to C). ${ }^{22}$

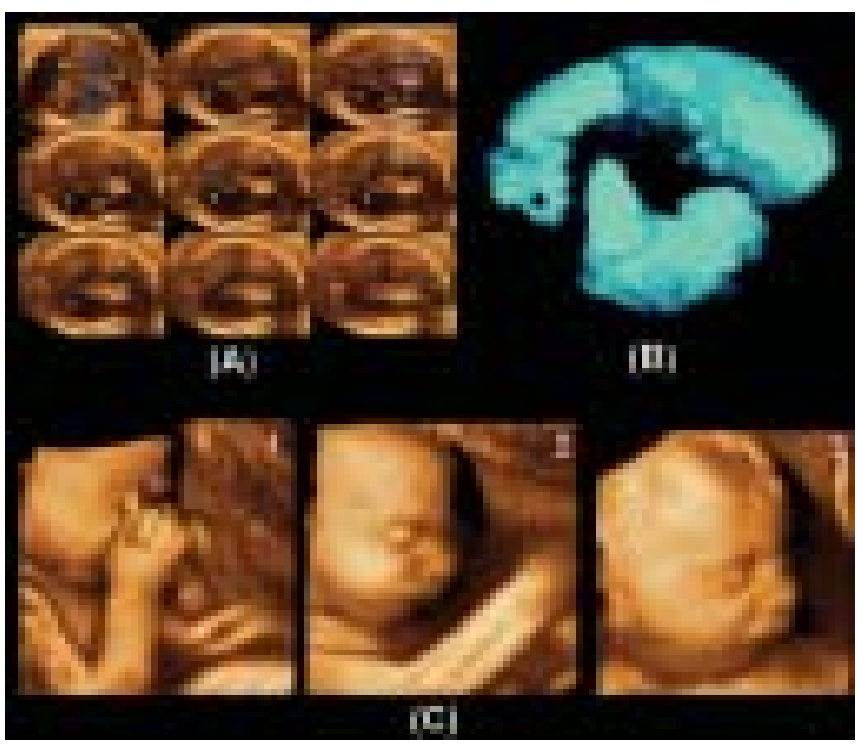

Figs 7A to C: (A) Tomographic ultrasound imaging of fetal hydrocephalus (arrow); (B) Visualization of entire cerebrospinal fluid in hydrocephalus using 3D inverse mode; (C) Changing of facial expression of hydrocephalic fetus can be observed using 4D sonographic technique

\section{Dandy-Walker Malformation}

Dandy Walker malformation (DWM) is a rare congenital anomaly of the central nervous system characterized by a complex developmental abnormality of the posterior fossa, mainly featured by posterior fossa cyst and a defect in the cerebellar vermis through with the cyst communicates with the fourth ventricles (Figs $8 \mathrm{~A}$ to $\mathrm{C}$ ). ${ }^{1-3,10,23}$ The size of the cyst and the defect in the cerebellar vermis may encompass a wide spectrum. Complete absent of the vermis with a large posterior fossa cyst might be found. In other cases, the defect may involve only the

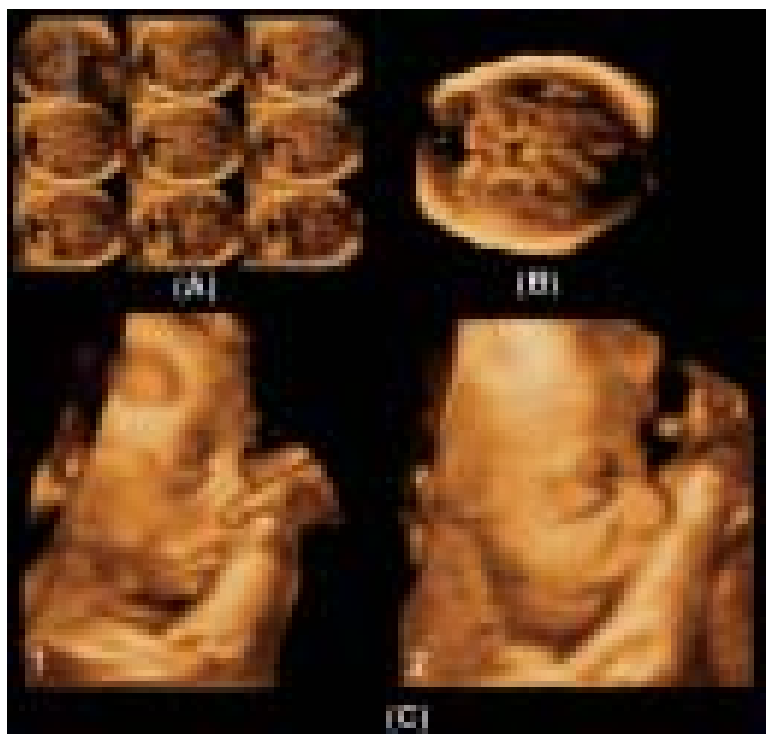

Figs 8A to C: (A) Tomographic ultrasound imaging of Dandy-Walker malformation (arrow); (B) Visualization of enlarge cysterna magna and defect in the posterior fossa by 3D surface imaging; (C) Changing of facial expression and hand movement can be observed using 4D sonographic technique 
posterior-inferior portion of the vermis, and the cyst may be small. DWM is frequently associated with obstructive ventriculomegaly and responsible for 12 percent cases of hydrocephalus. $^{23}$

\section{Acrania and Anencephaly}

An acrania could be diagnosed as early as 7th week of gestation by depicting the absence of the skull and deformed brain tissue without showing brain ventricle structures two dimensionally. ${ }^{1-3,24}$ Moreover, even by the 9 to 10 weeks scan, the condition can be overlooked because depicting the optimal section is difficult. To prevent this, observation by 3DUS is useful. By the multiplanar display, depicting the correct sagittal section and coronal section, acrania and anencephaly are rather easily diagnosed. Also by the 3D surface mode, the abnormality of the head is shown more clearly (Fig. 9). ${ }^{5}$

\section{Spina Bifida}

Spina bifida is a failure of closure of the neural tube, which normally occurs by the sixth week of gestation. ${ }^{1-3}$ The neural tube itself can be delineated as two parallel lines in the coronal lection of an embryo as early as 7 th week of gestation. ${ }^{25}$ The closure of the neural canal at 7th week of gestation should be confirmed by visualization of three ossification centers as it is presented from the 10th week of gestation. Blaas and colleagues $^{26}$ reported successful detection of three cases of lumbosacral myelomeningocele. However, we believe that 3D surface imaging makes a significant contribution to the accurate diagnosis of myelomeningocele, because it can demonstrate the spinal area very clearly (Fig. 10). By using 3D equipment, Bonilla-Musoles successfully showed a surface image of spina bifida and myelomeningocele at 9.5 weeks of gestation. ${ }^{27}$

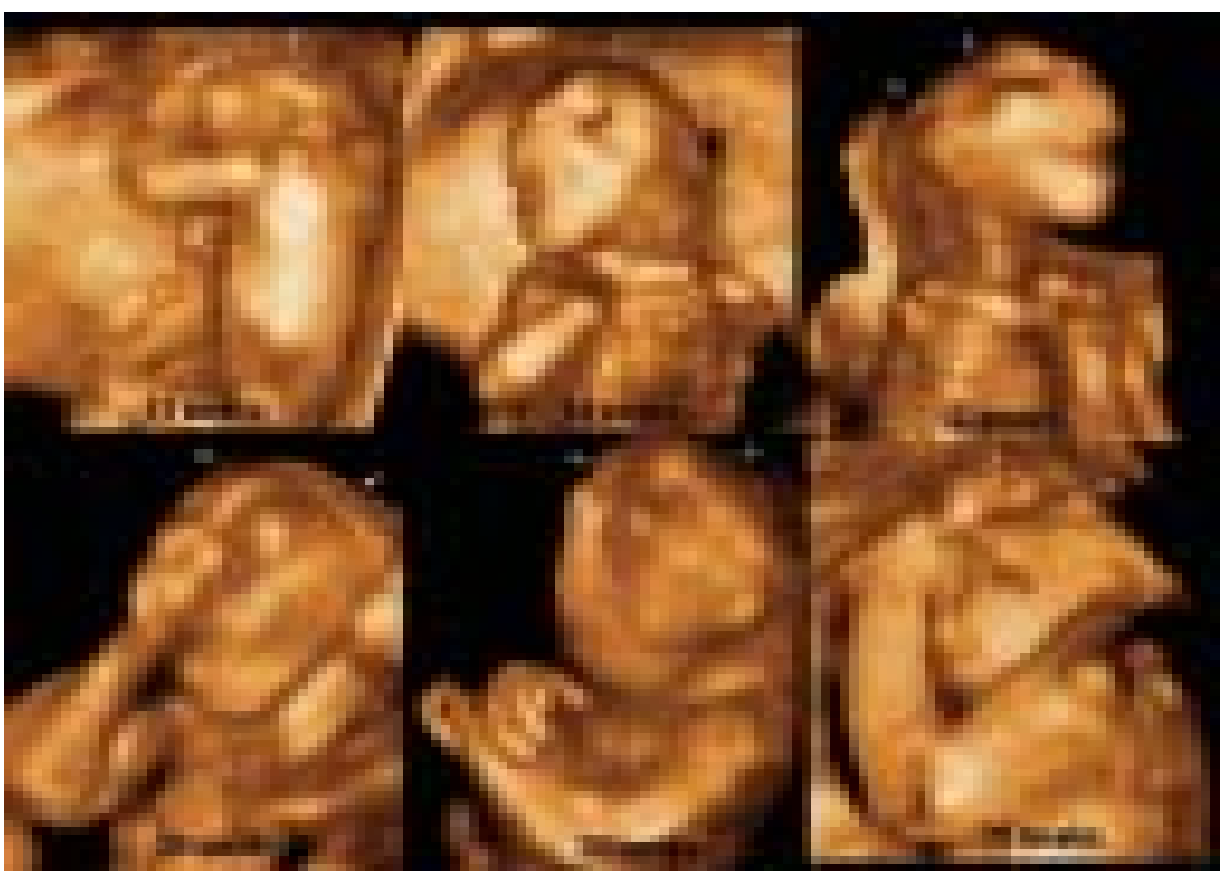

Fig. 9: Visualization of anencephalic fetus depicted by 3D surface imaging from different gestational age

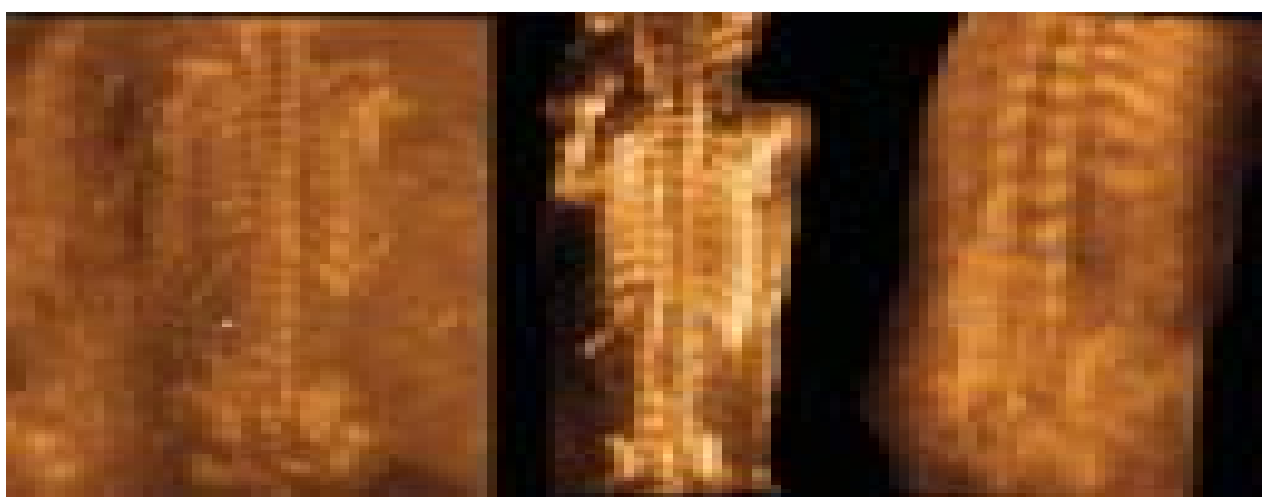

Fig. 10: Visualization of spina bifida depicted by 3D maximum mode and surface rendering (arrow) 


\section{Cephalocele and Sacral Meningocele}

The term cephalocele is often used for all three malformations as meningocele, meningoencephalocele and meningohydroencephalocele. ${ }^{28}$ If the defect of the cranium is small, only the meningens can bulge through it, and this anomaly known as meningocele. If the cranial opening is large, part of the brain and even part of the ventricle can herniated into the meningeal sac, forming a meningoencephalocele or meningohydroencephalocele (Figs 11A to C).

Sacral meningocele is a herniation of the meningeal sac into the extra peritoneal pelvic region through a congenital defect in the sacrum. ${ }^{29}$ The herniated sac is composed of two layers: the outer dural sac, and the inner arachnoid membrane. The sac contains cerebrospinal fluid with no neural elements (Fig. 11C).

\section{Omphalocele}

All fetuses, at 8th to 10th weeks demonstrate herniation of the midgut that is visualized as an hyperechogenic mass at the base of the umbilical cord. ${ }^{1-3}$ Retraction of the midgut into the abdominal cavity is completed by the end of the 11th week. Accordingly, even before 12th week of gestation, pathological herniation can be diagnosed by the shape and size of the herniated mass (Figs $12 \mathrm{~A}$ to $\mathrm{C}$ ). ${ }^{30,31}$

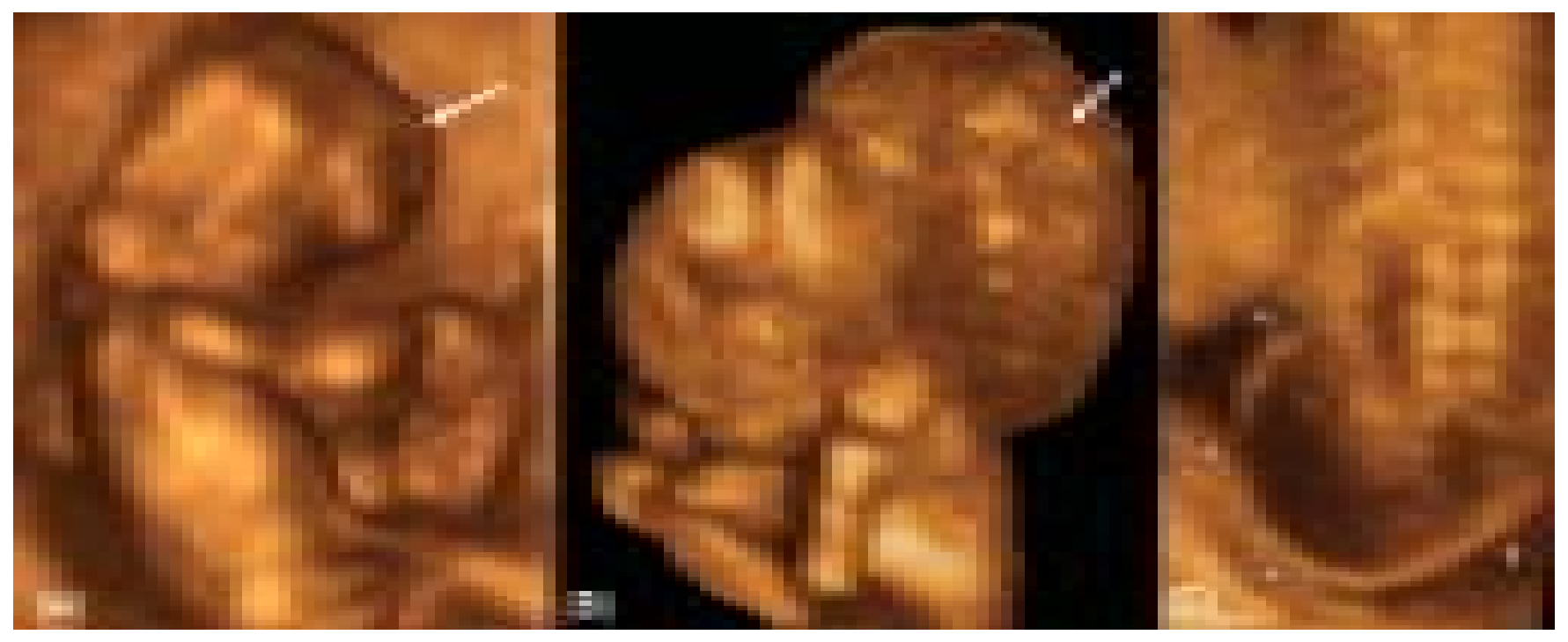

Figs 11A to C: Visualization of cephalocele and sacral meningocele depicted by 3D surface imaging

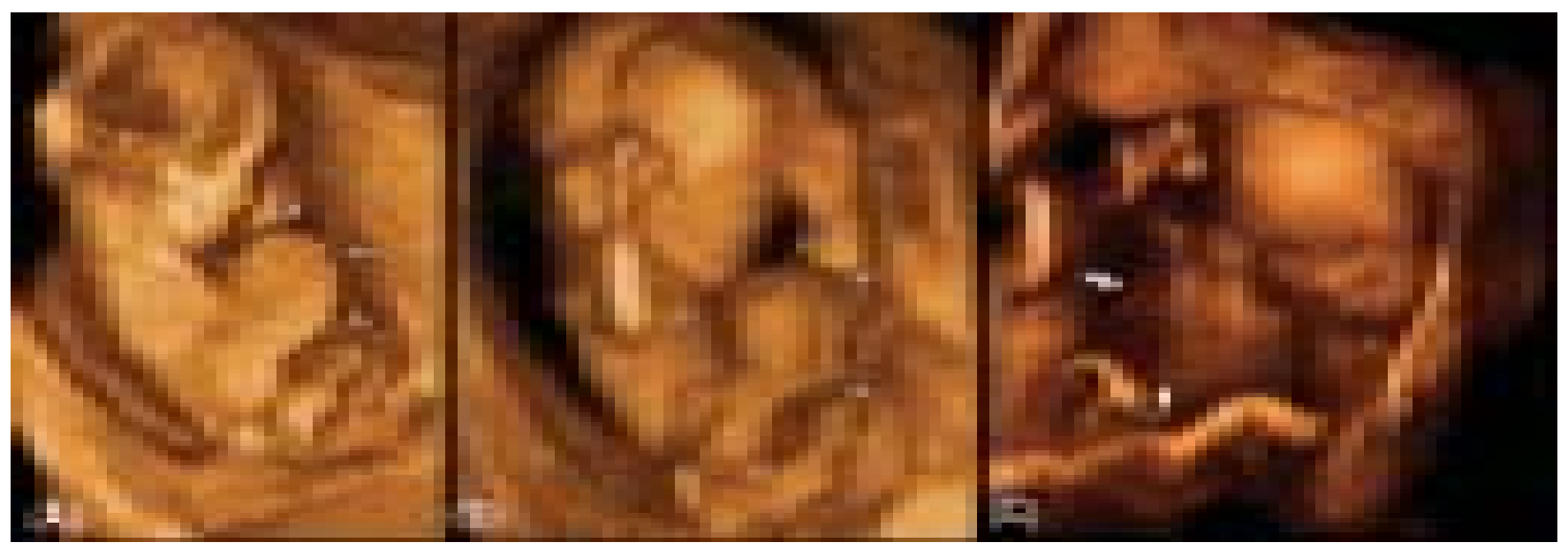

Figs 12A to C: 3D surface imaging of omphalocele. Note the bulging of mesenteric structure outside abdomen can be clearly depicted (arrow) 


\section{Diaphragmatic Hernia}

Diaphragmatic hernia could be diagnosed during the second and third trimesters of pregnancy by the ultrasonographic demonstration of intrathoracic viscera and mediastinal shift to the opposite side (Figs 13A and B). Development of diaphragmatic hernia is usually completed by the 9th week of gestation. In the presence of a defective diaphragm, there is herniation of the abdominal viscera into the thorax at about 10th to 12th weeks, when the intestines return to the abdominal cavity from the umbilical cord. In about 50 percent of affected fetus, there are associated chromosomal abnormalities or other defects. $^{32}$

\section{Meconium Peritonitis}

Meconium peritonitis is a rare condition which was associated with a short bowel and complicated by progressive bowel distension and difficulty in making a definitive diagnosis of cystic fibrosis. ${ }^{33}$ It is a sterile chemical peritonitis induced by meconium extruding into the peritoneal cavity through a perforation in the intestine, proximal to the site of obstruction and causing peritoneal irritation (Figs 14A and B). When the diagnosed of meconium peritonitis made antenatally, the main decision that have to be made are when and how to deliver the baby.

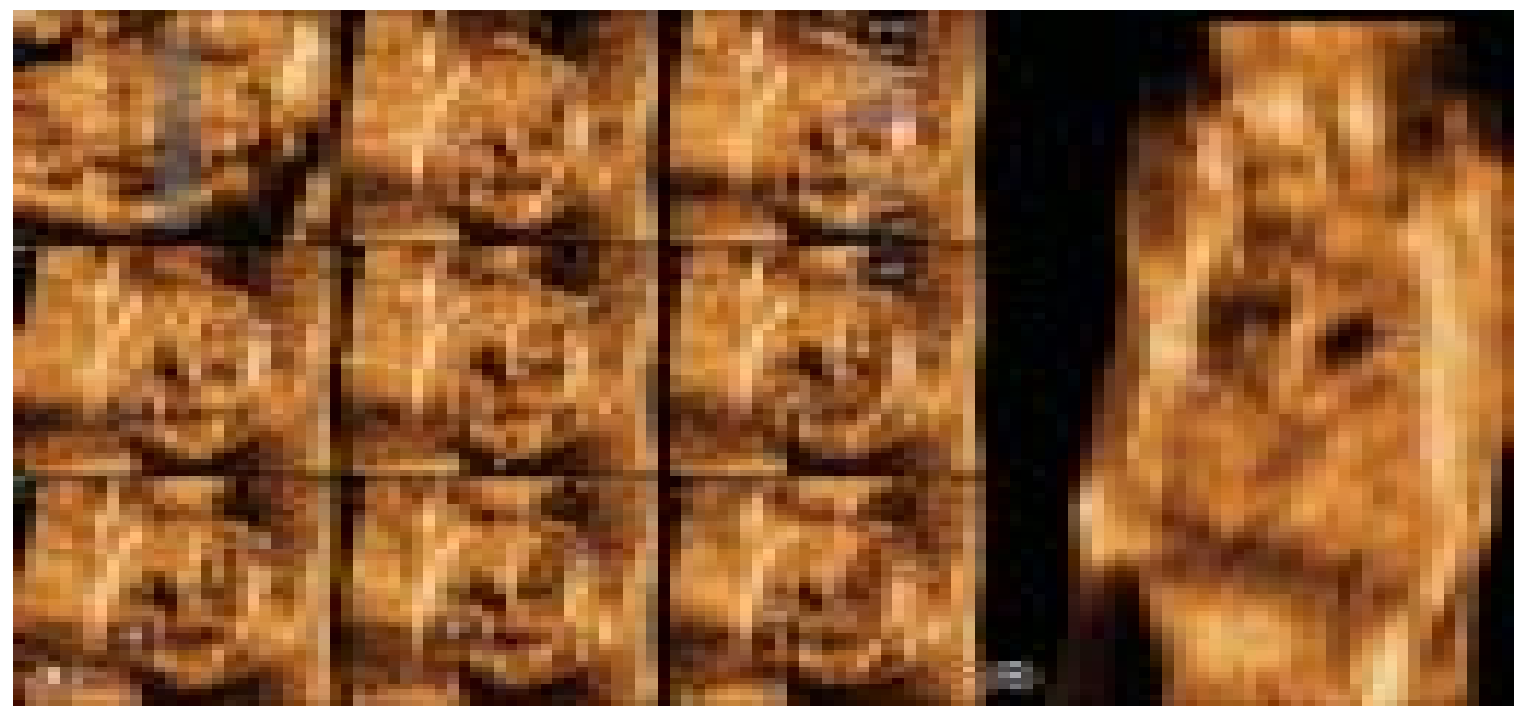

Figs 13A and B: (A) Tomographic ultrasound imaging demonstrated level of the diaphragmatic hernia; (B) Using 3D multiplanar technique, visualization of diaphragmatic hernia (arrow) can be shown from the frontal axis

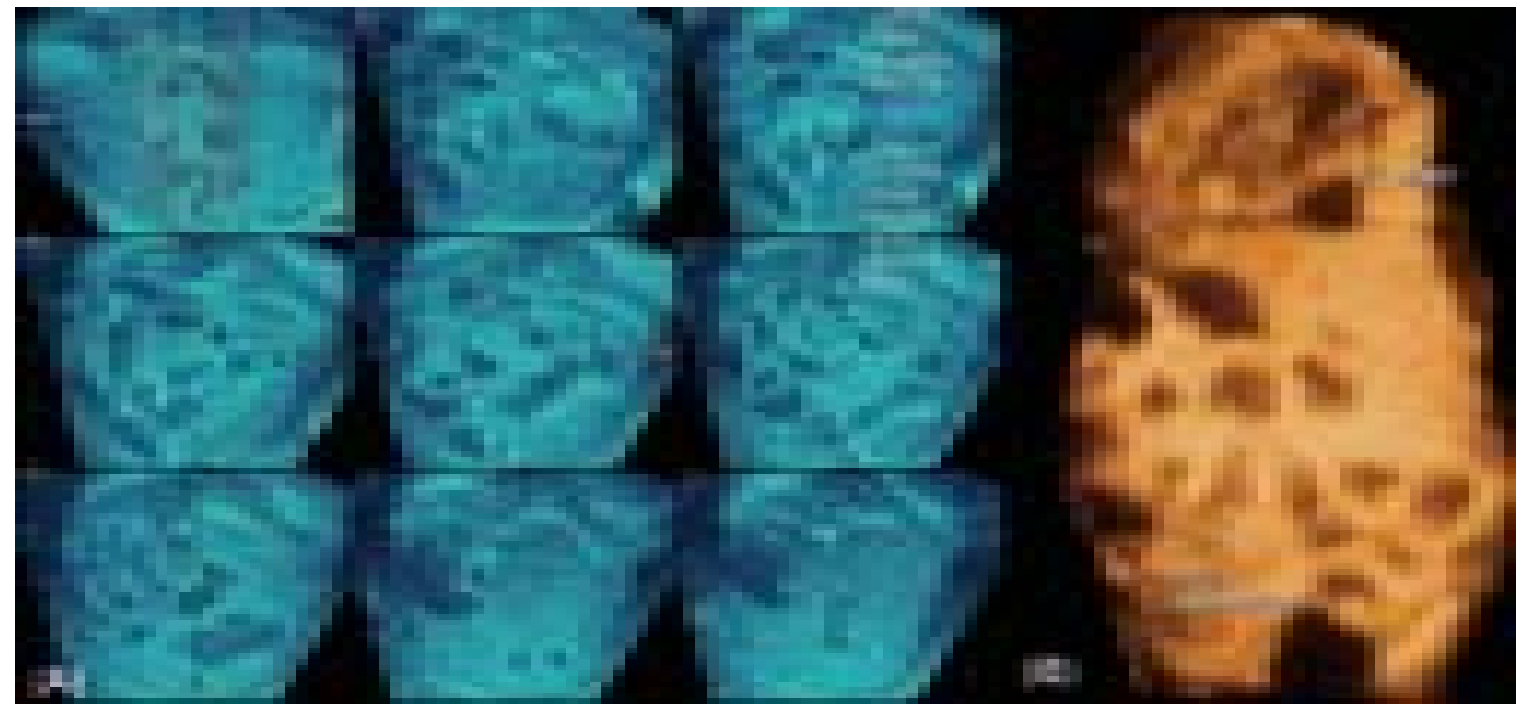

Figs 14A and B: (A) Tomographic ultrasound imaging demonstrated meconium peritonitis; (B) Visualization of meconium peritonitis from the frontal axis 


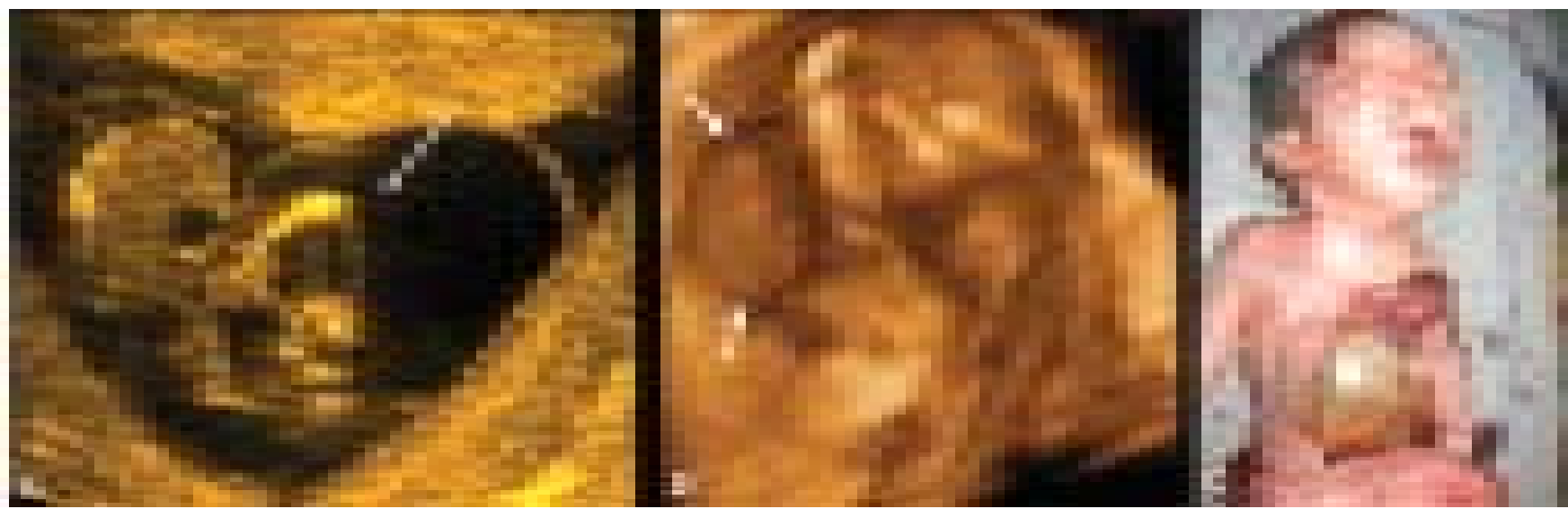

Figs 15A to C: (A) 2D US imaging of VACTERL association demonstrating ectopic heart;

(B) 3D surface imaging shown ectopic heart (arrow); (C) Illustration of newborn complicated by VACTERL association

\section{VACTERL Association}

VACTERL is a useful acronym for a nonrandom association of malformations including V (vertebral anomalies), A (anal atresia), C (cardiac anomalies), TE (tracheoesophageal fistula or esophageal atresia), R (renal/urinary anomalies), and L (limb defect). Patients are considered to have the VACTERL association when 3 or more organ systems are involved. ${ }^{34}$ The most frequent defects described are tracheoesophageal fistula and anal or vertebral anomalies. The diagnosis can also be suspected because of polyhydramnios in the presence of a small or absent fetal stomach (the tracheoesophageal fistula), hemivertebrae or scoliosis, or limb (in particular, radius anomalies, club hand, reduction defects, and polydactylies), renal, and cardiac defects. The ultrasound diagnosis of VACTERL syndrome may be accomplished early in the second trimester, if the fetus is severely affected (Figs 15A to C). ${ }^{34}$

\section{Campomelic Dysplasia}

Campomelic dysplasia is a congenital disorder characterized by development of abnormal curvature of the long bones, particularly from lower extremities, such as femur and tibiae (Fig. 16). ${ }^{35}$ Other author have classified the disease into two varieties: "long limbed" and "short limbed," depending on the type of limbs involved in the pathological process. ${ }^{36}$ Other sonographic features that are commonly present include, growth restriction, bell-shaped narrow chest, eleven pair of ribs, hypoplasia of the mid-thoracic vertebral bodies, fibula, and scapula, scoliosis, shortness of the limbs, talipes equinovarus, tracheobronchomalacia, flat and small face, high forehead with prominent occiput, low nasal bridge, micrognathia, cleft of the soft palate, hypertelorism, low-set and malformed ears, hydrocephalus, and ambiguous genitalia. ${ }^{35,36}$

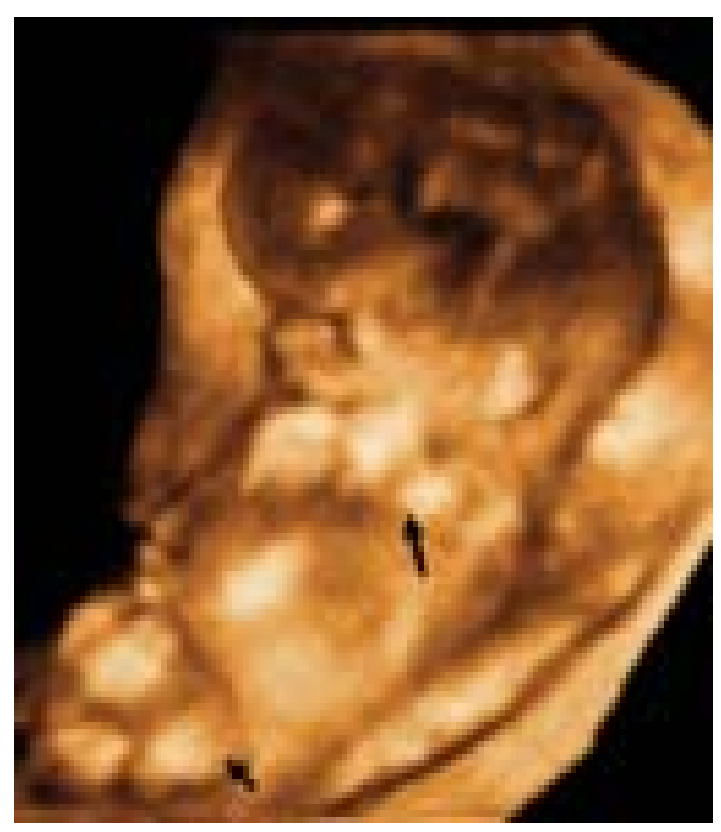

Fig. 16: Campomelic dysplasia depicted by 3D surface imaging. Note the short inferior and superior extremities can be cleary seen

\section{Achondroplasia}

Achondroplasia is associated with frontal bossing and low nasal bridge. ${ }^{37}$ The micromelia is the most obvious finding with limbs shorter than the 5th percentile after 20 weeks. The frontal bossing and depressed nasal bridge can also be recognized by 3D surface rendering (Figs 17A to C). Occasionally more subtle anomalies such as the trident hand (an increased interspace between the 3rd and 4th digits) or the lack of widening of the lumbar canal can also be identified. Children with achondroplasia have normal intellectual achievements. 


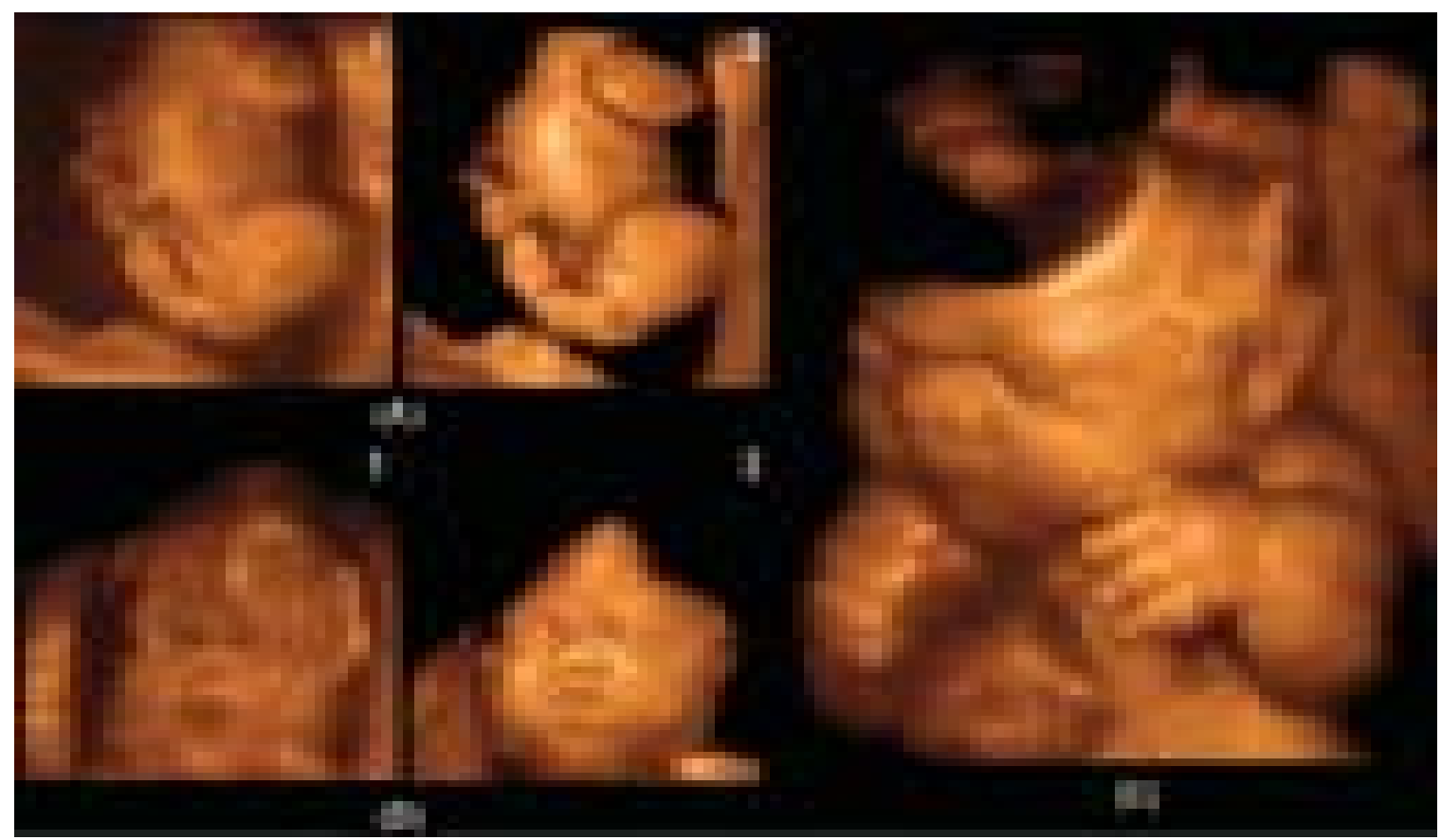

Figs 17A to C: (A) Visualization of lower extremity in the fetus complicated by achodroplasia; (B) Frontal bossing of the head can be clearly note in this anomaly; (C) Illustration of facial anatomy and upper limb structure of anchondroplasia characterized by short limb dysplasia

\section{Cleft Lip with Cleft Palate}

Cleft lip with cleft palate is a defect in the upper lip and alveolar ridge caused by failure of normal migration or fusion of the maxillary processes and the medial nasal process. ${ }^{4,38}$ Standardized 3D multiplanar images allow a systematic evaluation of lip defects and abnormalities of the maxillary tooth-bearing alveolar ridge (Figs 18A and B). The accuracy of adjunctive 3DUS is superior to 2D ultrasound alone for extensive prenatal diagnosis of cleft lip with or without cleft primary palate. ${ }^{38}$

\section{Arthrogryposis Multiplex Congenita}

This heterogeneous set of this malformation shares limitation of movements and joint ankylosis as main findings. ${ }^{39}$ The prenatal diagnosis may be challenging when fluid is decreased, and the abnormal limb position appears attributable to the oligohydramnios. Some forms are associated with polyhydramnios and then the abnormal limb position (knocked knee), genu recurvatum, clubfeet and hand make the diagnosis easy (Figs 19A and B). Polyhydramnios is often a manifestation of decreased swallowing, which may be part of the same pathogenesis as the arthrogryposis itself (muscular or neuronal deficit). ${ }^{39}$

\section{Sacrococcygeal Teratoma}

The sacrococcygeal teratoma is defined as a neoplasm composed of tissues from all three germ layers. ${ }^{40}$ The most

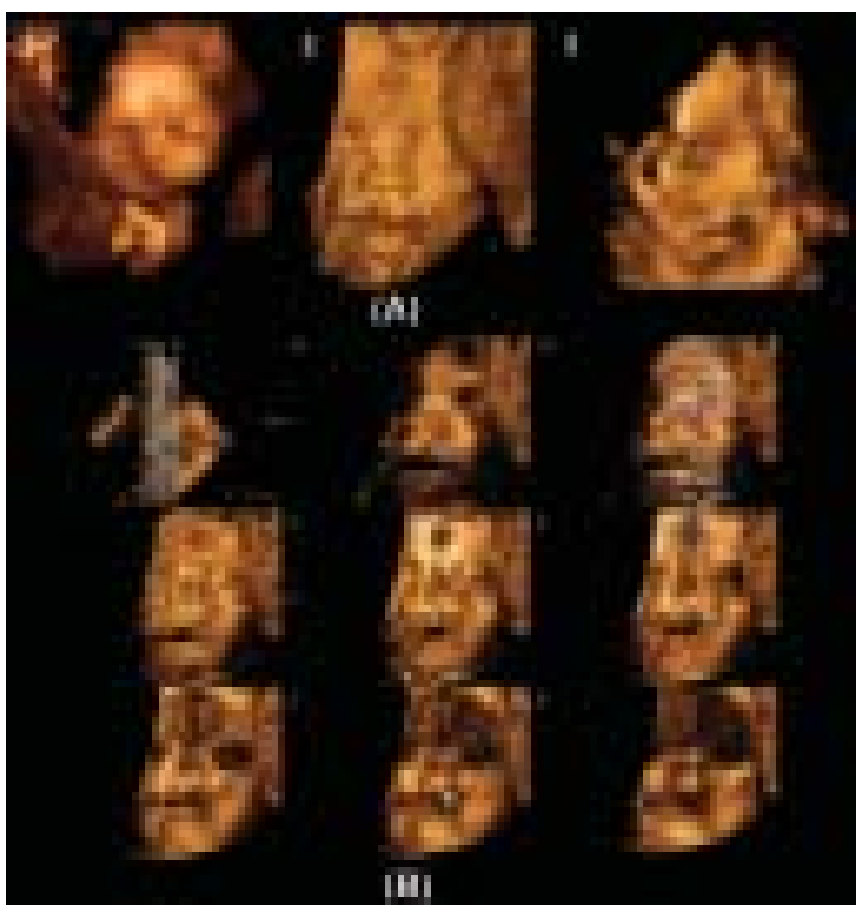

Figs 18A and B: (A) 3D surface imaging of the fetus complicated by cleft lip with cleft palate. (B) Tomographic ultrasound imaging demonstrated slice-by-slice facial anatomy in this anomaly 


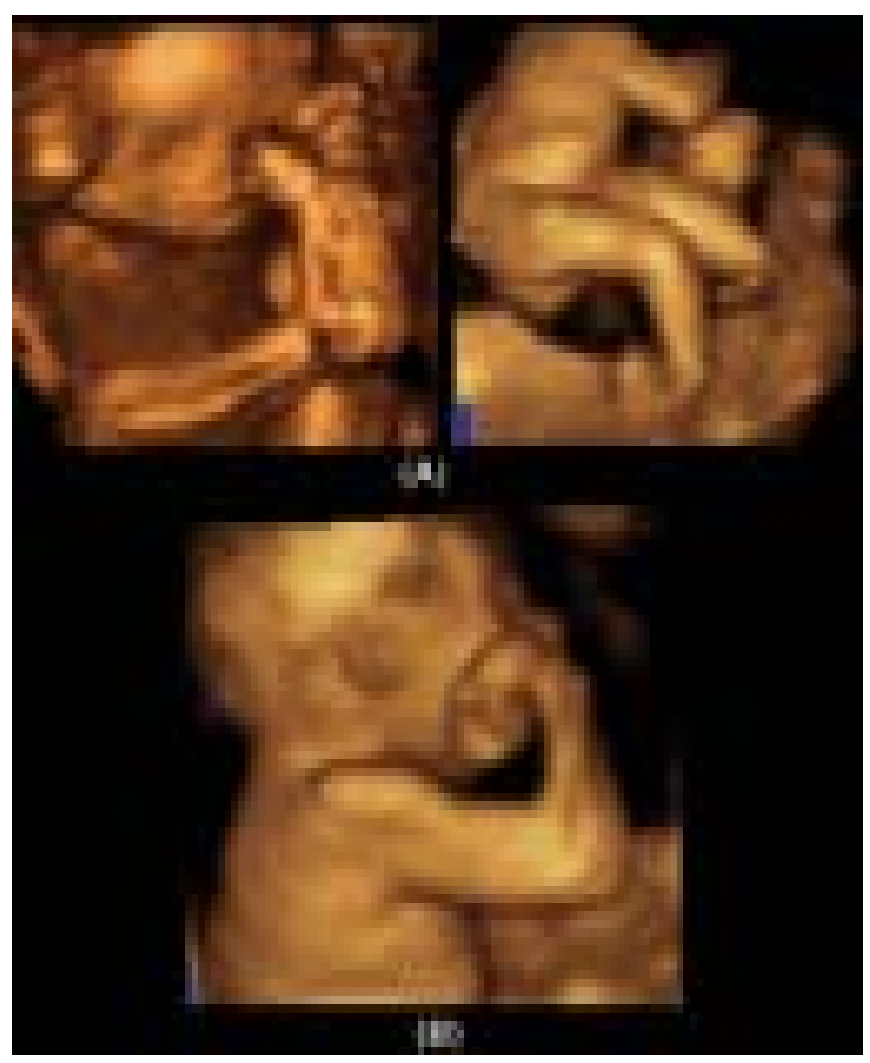

Figs 19A and B: Visualization of clubfoot $(A)$ by $3 D$ surface imaging in the fetus complicated by arthrogryposis multiplex congenital (B) common sites are the sacrococyx, although they may occur near the midline from the brain to the coccyx. Most of these tumors are solid or mixed solid and cystic (Fig. 20). Polyhydramnios is a common sign and non-immune hydrops have also been seen in association. The benign neoplasm can transform into malignancy. The surgical removal is advisable. ${ }^{40}$

\section{Hydronephrosis}

Hydronephrosis is characterized by the dilatation of calices and renal pelvis. ${ }^{41}$ It can be obstructive or not. The most frequent cause of obstructive hydronephrosis is the stenosis of the ureteropelvic junction, being bilateral in between 10 to 15 percent of cases. The imaging study will vary in accordance with the degree of obstruction at the pyeloureteral junction. A proper diagnosis requires the dilatation of calices, and, most importantly, renal pelvis, without dilatation of the corresponding ureter (Figs 21A and B).

\section{Meckel Gruber Syndrome}

Meckel Gruber syndrome has very poor prognosis, inherited as an autosomal recessive, detected by the present of the classic triad of cystic renal dysplasia, occipital cephalocele and polydactyly and ambiguous external genitalia in males. ${ }^{42}$ Oligohydramnios has been reported and this condition will prevent visualization of cephalocele. In this case other abnormalities may lead to the correct diagnosis (Figs 22A to F).

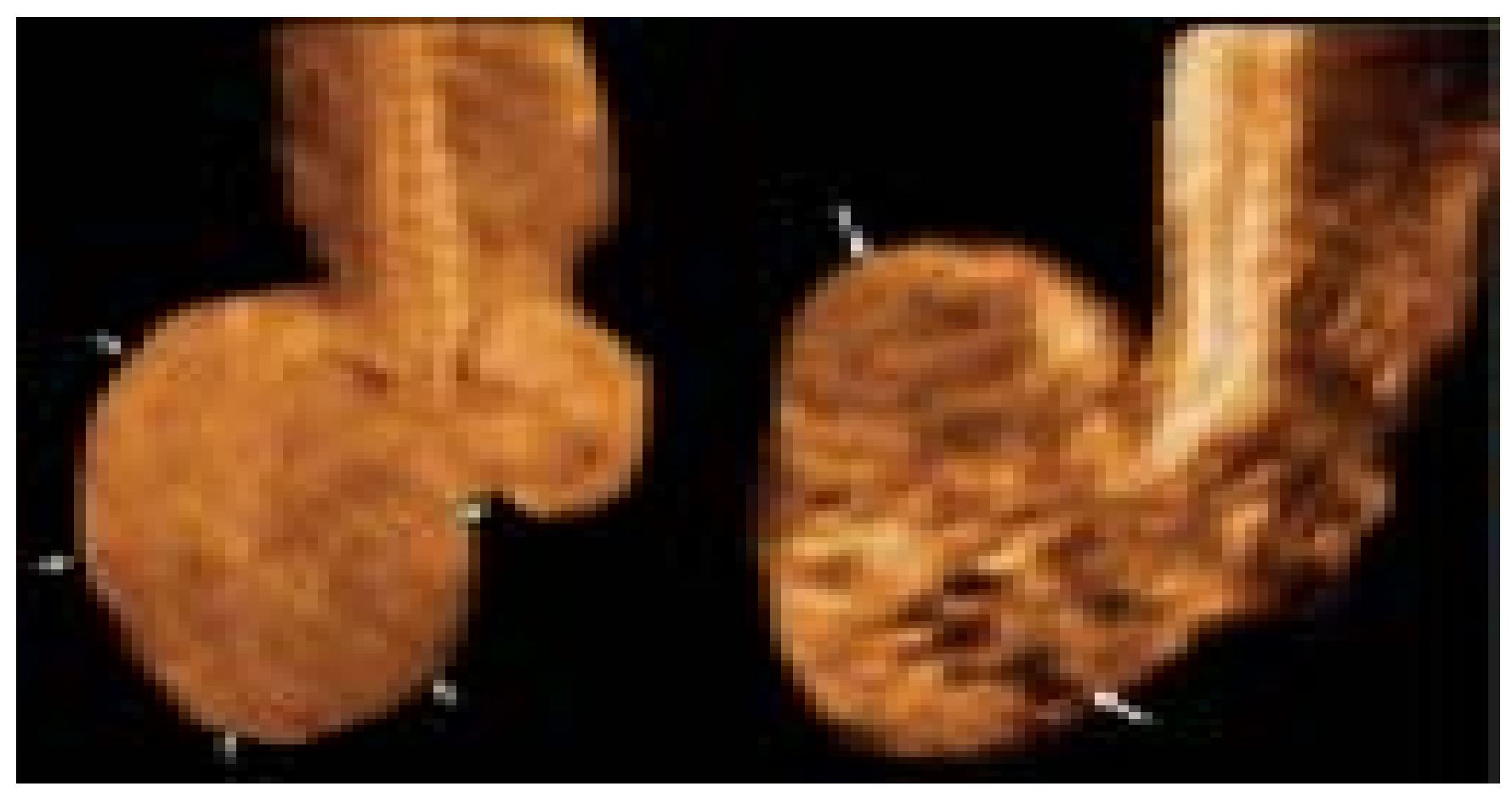

Fig. 20: Solid and cystic structure of sacrococcygeal teratoma can clearly depicted by 3D surface imaging 


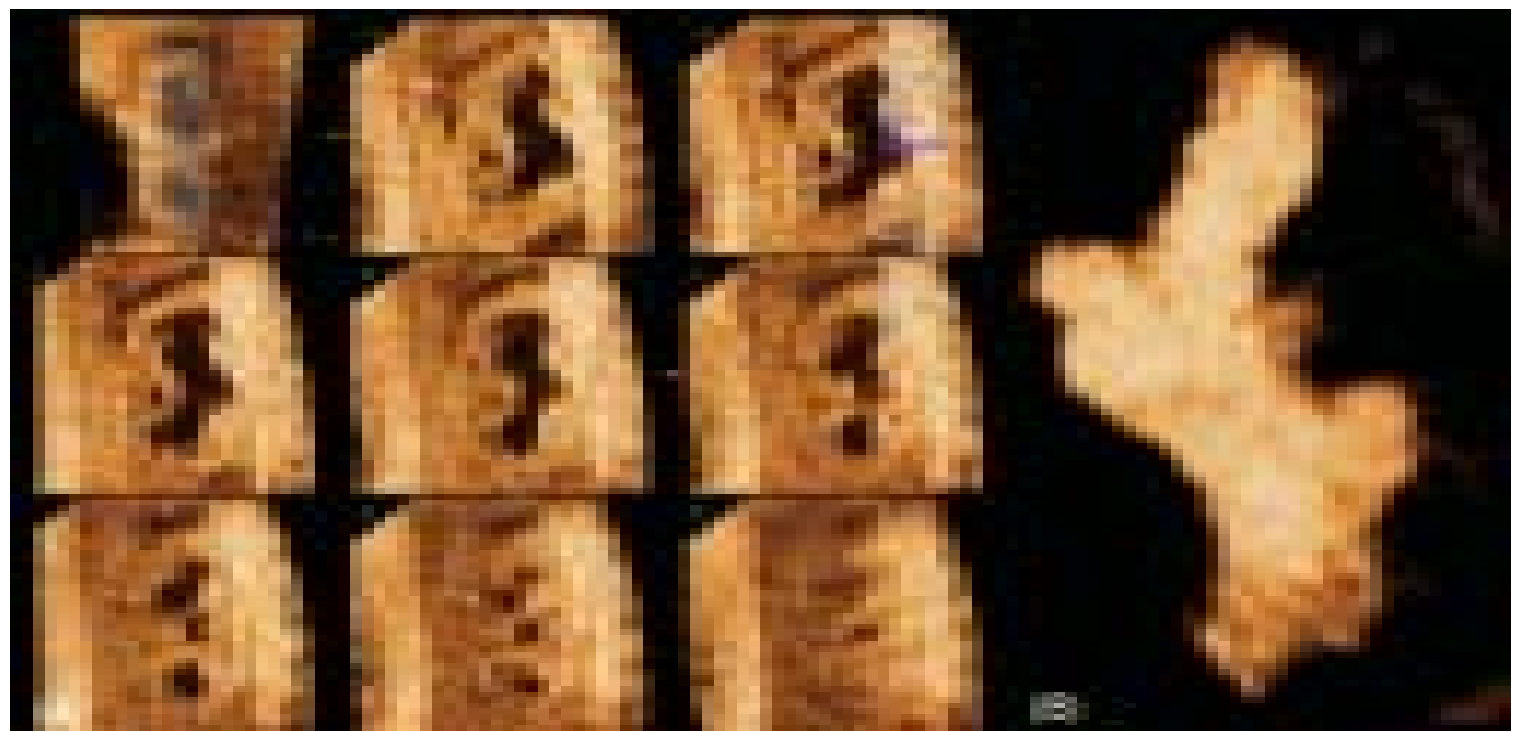

Figs 21A and B: (A) Tomographic ultrasound imaging of fetal hydronephrosis demonstrated enlarge renal pelvis; (B) Visualization of the enlarge renal pelvis volume depicted by 3D inverse mode

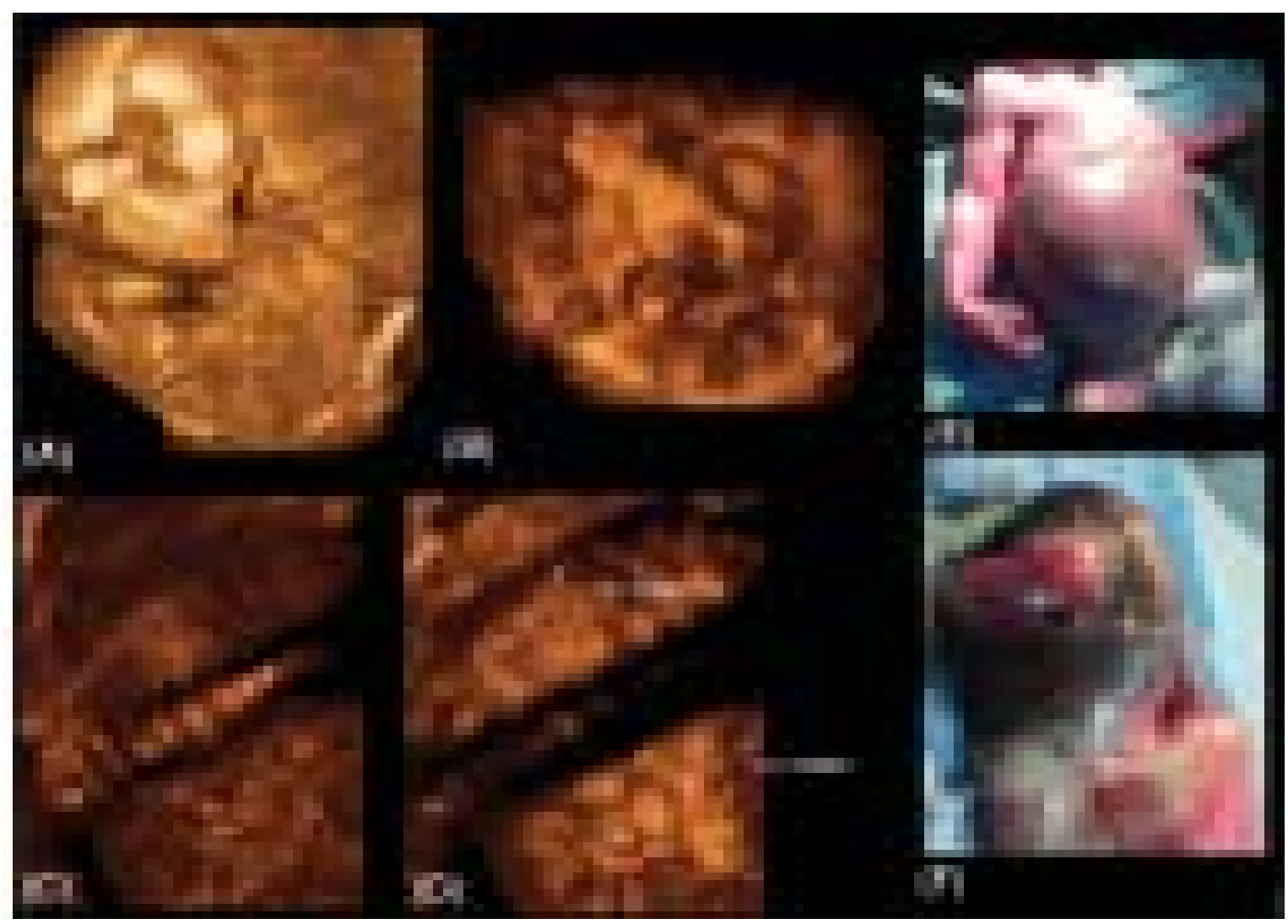

Figs 22A to F: (A) Meckel Gruber syndrome diagnosed by 3DUS at 17th week of gestation; (B to D) Bilateral multicystic kidney could be clearly visualized by 3D surface imaging in Meckel Gruber syndrome; (E-F) Illustration of newborn complicated by this anomaly demonstrated enlarge abdomen and small encephalocele 


\section{Polycystic Kidney}

The polycystic renal disease displays a recessive autosomal inheritance with an early intrauterine manifestation. It is the most common heritable cystic renal disease occurring in infancy. ${ }^{43}$ The prenatal diagnosis is done by ultrasound showing the enlarged kidneys, oligohydramnios and occasionally the presence of ascites (Figs 23A and B). The anomaly was previously called infantile polycystic renal disease. It is characterized by cystic dilation of the renal tubules and is often associated with congenital hepatic fibrosis. It is commonly prenatally visualized, but it can have a later manifestation in some cases.

\section{Prune-Belly Syndrome}

Prune-belly syndrome is a rare congenital disorder, more common in males, consisting of deficiency of abdominal wall muscles (absent or hypoplastic), cryptorchidism, and genitourinary malformations. The ultrasound diagnosis was based on the findings of a lower abdominal cystic echo caused by abnormal dilatation of the bladder (Figs 24A and B). It is not a single entity and various abdominal lesions can cause the abnormal fetal appearance of abdominal wall laxity or wrinkling. It is a syndrome characterized by a spectrum of abnormalities, and patients can be categorized according to the severity of the symptoms. The most severe form is characterized by progressive

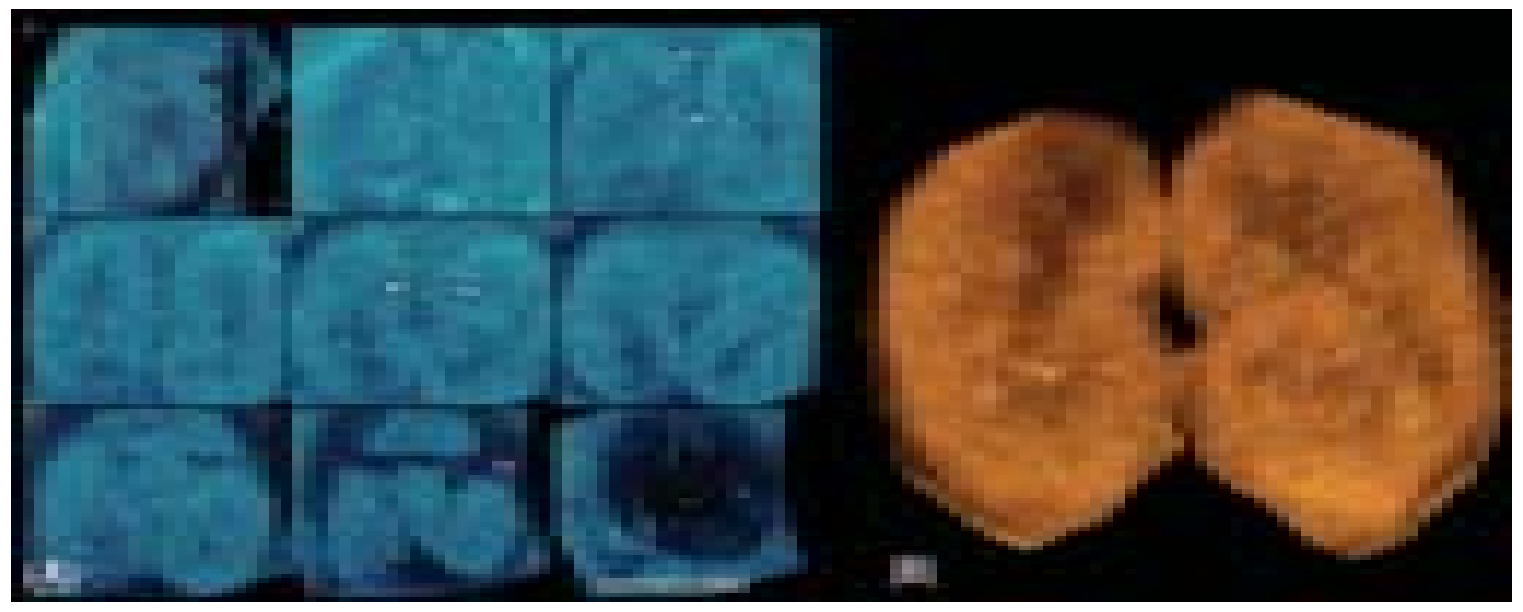

Figs 23A and B: (A) Tomographic ultrasound imaging of bilateral multicystic kidney; (B) Visualization of enlarge kidney in this anomaly by 3D surface imaging

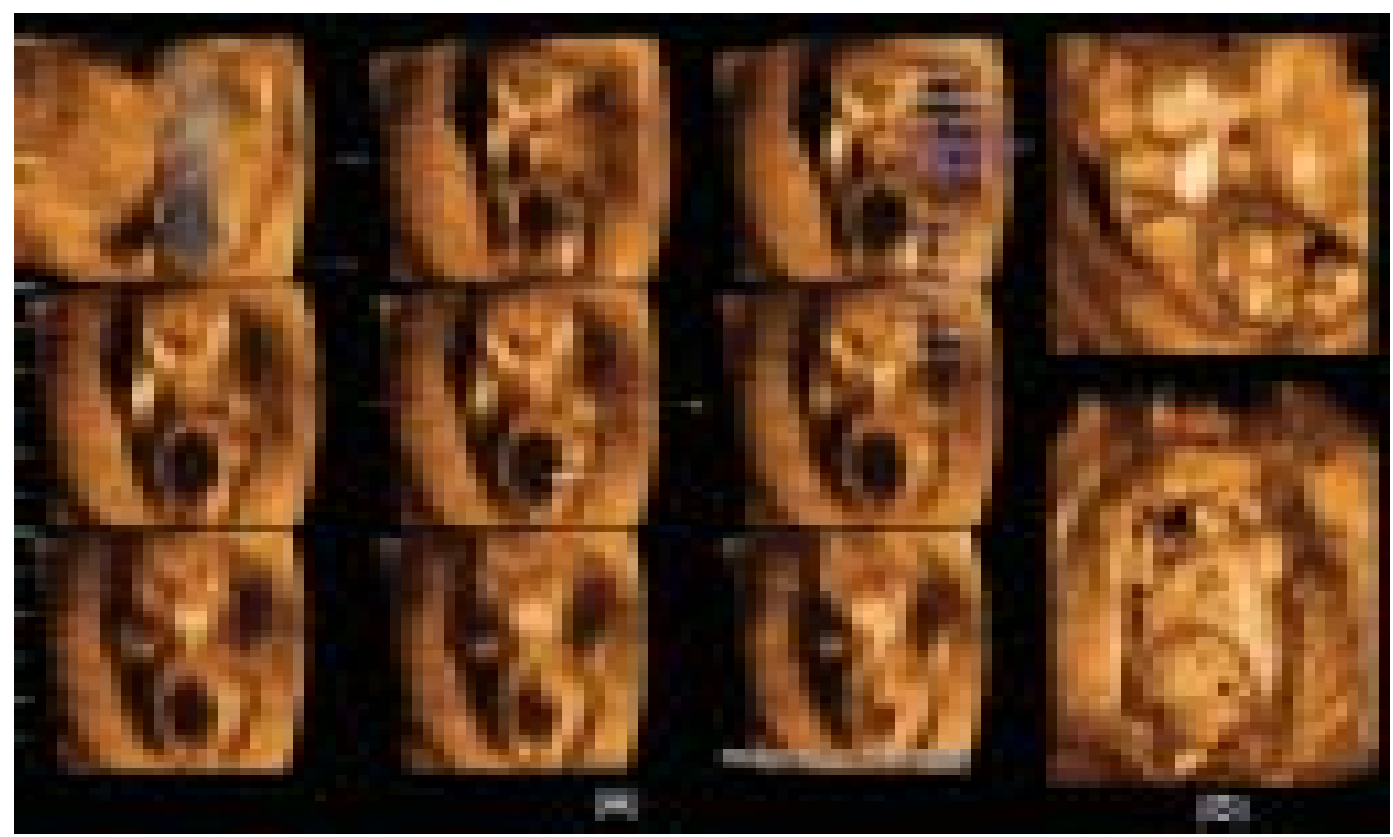

Figs 24A and B: (A) Tomographic ultrasound imaging of fetus complicated by prune-belly syndrome (arrow); (B) Visualization of this anomaly by 3D surface imaging 


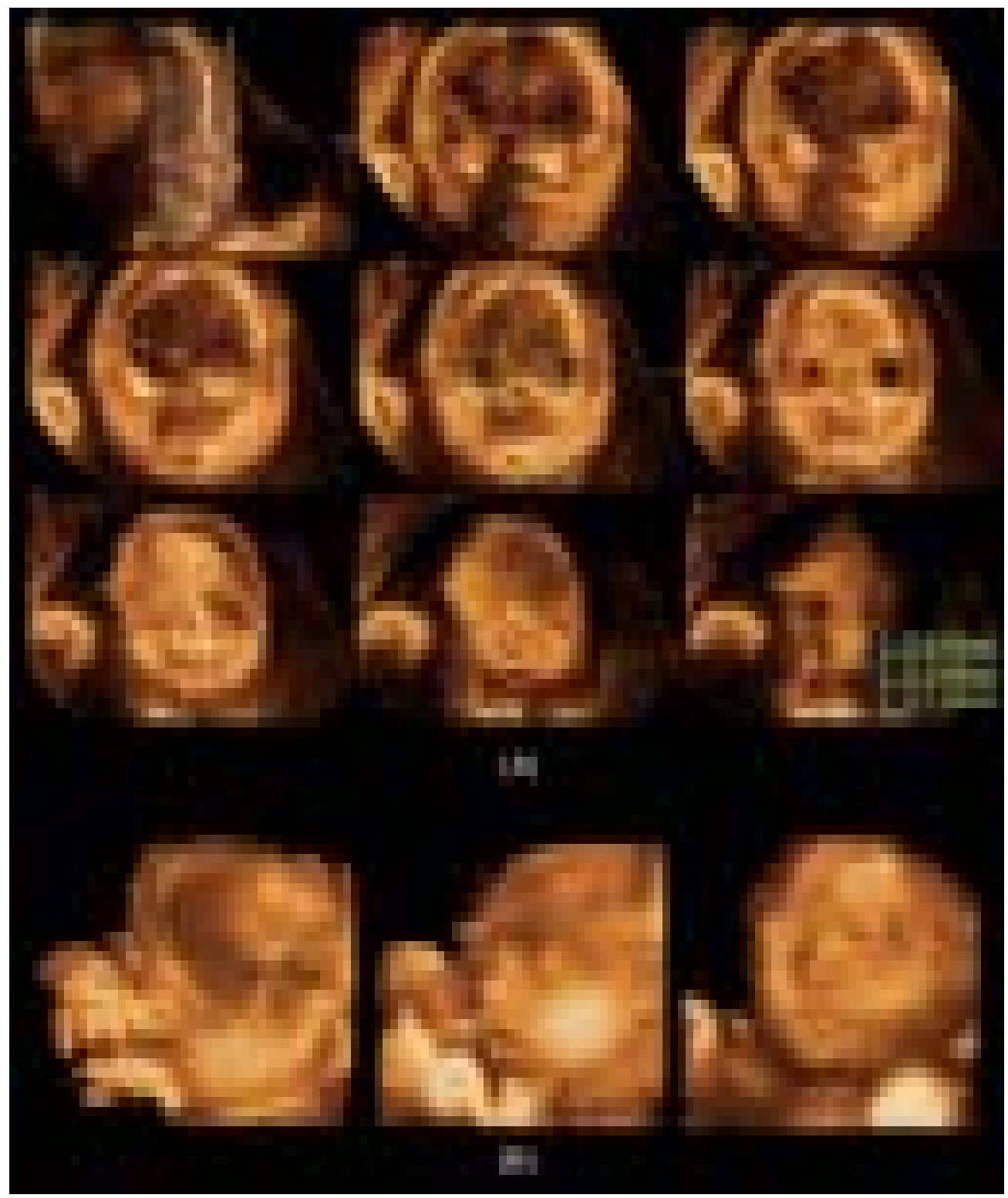

Figs 25A and B: (A) Tomographic ultrasound imaging demonstrated slice-by-slice facial anatomy and level of the hypertelorism in trisomy 18; (B) Visualization of rounded face and hypertelorism in trisomy 18 by 3DUS

distention of the prune-belly-like bladder leading to oligohydramnios, pulmonary hypoplasia, and ultimately stillbirth. ${ }^{1-3,44}$

\section{Trisomy 18}

Trisomy 18 was first reported by Edward in 1960 and has prevalence of 1 in 3000 births. It shows female preponderance and occurs more frequently with increase maternal age. The prognosis of this trisomy 18 is extremely poor with 30 percent dying in the first month of life and only 10 percent surviving to the end of the first year with severely mentally retarded. Several malformations like hand malformation, rocker bottom feet, choroid plexus cyst, omphalocele were found in this case. Of particular interest was the strawberry-shaped head observed whilst measuring head circumference. Hypertelorism was found as an increased interorbital distance associated with this malformations (Figs 25A and B). ${ }^{45}$

\section{CONCLUSION}

For the time being, 3DUS are not yet widely used in obstetrics on a routine basis for diagnosing fetal abnormalities. Their roles are still being evaluated in several perinatal areas. However, this powerful tool provides additional information for the diagnosis and assessment of facial anomalies, neural tube 
defects, and skeletal malformations. Additional research is needed to determine the clinical role of 3DUS for the diagnosis of congenital heart disease, central nervous system (CNS) anomalies and detection of fetal neurodevelopmental damage. Through this review, we had tried to express the initial contribution of 3DUS in obstetric focused on abnormal structure. It is hoped that the advance of 3DUS with more sophisticated analysis softwares, development of ultrafast computers might enhance diagnosis of fetal anomalies. Although initial results are encouraging, there is still long way to go.

\section{REFERENCES}

1. Kurjak A, Pooh RK, Merce LT, Carrera JM, Salihagic-Kadic A, Andonotopo W. Structural and functional early human development assessed by three-dimensional and fourdimensional sonography. Fertil Steril 2005;84:1285-99.

2. Azumendi G, Arenas JB, Andonotopo W, Kurjak A. Threedimensional sonoembriology. In Kurjak A (Ed): Textbook of Transvaginal Sonography. London: Taylor \& Francis, 2005;396407.

3. Andonotopo W, Kurjak A, Azumendi G. Early normal pregnancy. In: Carrera JM, Kurjak A (Eds): Atlas of Clinical Application of Ultrasound in Obstetrics and Gynecology. Jaypee Brothers Medical Publishers: New Delhi 2006;25-50.

4. Azumendi G, Kurjak A, Carrera JM, Andonotopo W, Scazzochio E. 3D and 4D sonography in the evaluation of normal and abnormal fetal facial expression. In: Carrera JM, Kurjak A (Eds): Atlas of Clinical Application of Ultrasound in Obstetrics and Gynecology. Jaypee Brothers Medical Publishers: New Delhi, 2006;250-82.

5. Andonotopo W, Kurjak A, Ivancic-Kosuta M. Behavioral of anencephalic fetus studied by 4D sonography. J Matern Fetal Neonatal Med 2005;17:165-8.

6. Kurjak A, Stanojevic M, Andonotopo W, Scazzochio-Duenas E, Azumendi G, Carrera JM. Fetal behaviour assessed in all three trimesters of normal pregnancy by 4D ultrasonography. Croat Med J 2005;46:772-80.

7. Salihagic-Kadic A, Kurjak A, Medic M, Andonotopo W, Scazzochio-Duenas E, Azumendi G, et al. New data about embryonic and fetal neurodevelopment and behavior obtained by 3D and 4D sonography. J Perinat Med 2005;33:478-90.

8. Kurjak A, Andonotopo W, Hafner T, Salihagic-Kadic A, Stanojevic M, Azumendi G, et al. Normal standards for fetal neurobehavioral developments - longitudinal study by 4D sonography. J Perinat Med 2006;34:56-65.

9. Kurjak A, Kupesic S, Ivancic-Kosuta M. Three-dimensional transvaginal ultrasound improves measurement of nuchal translucency. J Perinat Med 1999;27:97-102.

10. Benoit B, Hafner T, Kurjak A, Kupesic S, Bekavac I, Bozek T. Three-dimensional sonoembryology. J Perinat Med 2002;30:6373.

11. Pretorius DH, Nelson TR. Three-dimensional ultrasound of fetal surface features. Ultrasound Obstet Gynecol 1992;2:166-8.
12. Lee A, Deutinger J, Bemaschek G. Three-dimensional ultrasound: abnormalities of the fetal face in surface and volume rendering mode. Br J Obstet Gynaecol 1995;102:40-3.

13. Lee A, Deutinger J, Bemaschek G. Voluvision: Threedimensional ultrasonography of fetal malformations. Am J Obstet Gynecol 1994;170:1312-4.

14. Lee A, Kratochwil, Deutinger J, Bernaschek G. Threedimensional ultrasound in diagnosing phocomelia. Ultrasound Obstet Gynecol 1995,5:238-40.

15. Bonilla-Musoles F, Raga F, Osbome N, Blanes J. Use of threedimensional (3D) ultrasound for study of normal pathologic morphology of the human embryo and fetus: Preliminary report. J Ultrasound Med 1995;14:757-65.

16. Trauffer PM, Anderson CE, Johnson A, Heeger S, Morgan P, Wapner RJ. The natural history of euploid pregnancies with first-trimester cystic hygromas. Am J Obstet Gynecol 1994;170:1279-84.

17. Santolaya J, Alley D, Jaffe R, Warsof SL. Antenatal classification of hydrops fetalis. Obstet Gynecol 1992;79:256-9.

18. Cullen MT, Green J, Whetham J, Salafia C, Gabrielli S, Hobbins JC. Transvaginal ultrasonographic detection of congenital anomalies in the first trimester. Am J Obstet Gynecol 1990;163:466-76.

19. Tan TYT, Sepulveda W. Acardiac twin: a systematic review of minimally invasive treatment modalities Ultrasound Obstet Gynecol 2003;22:409-19.

20. Steller MA, Genest DR, Bernstein MR, Lage JM, Goldstein DP, Berkowitz RS. Natural history of twin pregnancy with complete hydatidiform mole and coexisting fetus. Obstet Gynecol 1994;83:35-42.

21. Jauniaux E, Campbell S. Ultrasonographic assessment of placental abnormalities. Am J Obstet Gynecol 1990;163:16508.

22. Achiron R, Achiron A. Transvaginal ultrasonic assessment of the early fetal brain. Ultrasound Obstet Gynecol 1991;1:33644.

23. Pilu G, Goldstein I, Reece EA, Perolo A, Foschini MP, Hobbins JC, Bovicelli L. Sonography of fetal Dandy-Walker malformation: A reappraisal. Ultrasound Obstet Gynecol 1992;2:151-7.

24. Van ZaIen-Sprock RM, van Vugt JM, van Geijn HP. First and early second trimester diagnosis of anomalies of the central nervous system. J Ultrasound Med 1995;14:603-10.

25. Takeuchi H. Sonoembryology in the central nervous system. In Kurjak A, Chervenak A (Eds): The Fetus as a Patient. Carnforth, UK: Parthenon, 1994:141-50.

26. Blaas H-G, Eik-Nes SH, Isaksen CV. The detection of spina bifida before 10 gestational weeks using two- and threedimensional ultrasound. Ultrasound Obstet Gynecol 2000;16:209.

27. Bonilla-Musoles F. Three-dimensional visualization of the human embryo: A potential revolution in prenatal diagnosis [Editorial]. Ultrasound Obstet Gynecol 1996;7:393-7.

28. Budorick NE, Pretorius DH, McGahan JP, Grafe MR, James HE, Slivka J. Cephalocele detection in utero: sonographic and clinical features. Ultrasound Obstet Gynecol 1995;5:77-85. 
29. Andersen C and Tange M. Anterior sacral meningocele. Case report. Acta Chir Scand 1990;156:808-11.

30. Blaas HG, Eik-Nes SH, Kiserud T, Hellevik LR. Early development of the abdominal wall, stomach and heart from 7 to 12 weeks of gestation: A longitudinal study. Ultrasound Obstet Gynecol 1995;6:240-9.

31. Souka AP, Nicolaides KH. Diagnosis of fetal abnormalities at the 10-14 weeks scan. Ultrasound Obstet Gynecol 1997;10: 429-42.

32. Eroglu D, Yanik F, Sakallioglu AE, Arikan U, Varan B, Kuscu E. Prenatal diagnosis of bilateral diaphragmatic hernia by fetal sonography. J Obstet Gynaecol Res 2006;32:90-3.

33. Konje JC, de Chazal R, MacFadyen U, Taylor DJ. Antenatal diagnosis and management of meconium peritonitis: a case report and review of the literature.Ultrasound Obstet Gynecol 1995;6:66-9.

34. Benacerraf BR. VATER association in Ultrasound of fetal syndromes. Churchill Livingstone-New York - 1998;285-7.

35. Romero R, Pilu G, Jeanty P. et al. Prenatal diagnosis of congenital anomalies. Appleton and Lange, Norwalk, Connecticut, 1988.

36. Khajavi A, Lachman RS, Rimoin DL, Schimke RN, Dorst JP, Ebbin AJ, et al. Heterogeneity in the campomelic syndromes. Long and short bone varieties. Radiology 1976;120:641-7.

37. Ruano R, Molho M, Roume J, Ville Y. Prenatal diagnosis of fetal skeletal dysplasias by combining two-dimensional and threedimensional ultrasound and intrauterine three-dimensional helical computer tomography. Ultrasound Obstet Gynecol 2004; 24:134-140.
38. Mittermayer C, Blaicher W, Brugger PC, Beraschek G, Lee A. Foetal facial clefts: Prenatal evaluation of lip and primary palate by 2D and 3D ultrasound. Ultraschall Med 2004;25:120-5.

39. Hyett J, Noble P, Sebire NJ, Snijders R, Nicolaides KH. Lethal congenital arthrogryposis presents with increased nuchal translucency at 10-14 weeks of gestation. Ultrasound Obstet Gynecol 1997;9:310-3.

40. Roman AS, Monteagudo A, Timor-Tritsch I, Rebarber A. Firsttrimester diagnosis of sacrococcygeal teratoma: The role of threedimensional ultrasound. Ultrasound Obstet Gynecol 2004;23:612-4.

41. Romero R, Pilu G, Jeanty P, Ghidini A, Hobbins JC. Prenatal diagnosis of congenital anomalies. Norwalk, Conn: Appleton \& Lange, 1988.

42. Sepulveda W, Sebier NJ, Souka A, Snijders RJM, Nicolaides $\mathrm{KH}$. Diagnosis of the Meckel-Gruber syndrome at eleven to fourteen weeks' gestation. Am J Obstet Gynecol 1997;176: 3169.

43. Liu YP, Cheng SJ, Huang JK. Autosomal recessive polycystic kidney disease: appearance on fetal MRI. Pediat Radiol 2006;36:169.

44. Hoshino T, Ihara Y, Shirane H, Ota T. Prenatal diagnosis of prune belly syndrome at 12 weeks of pregnancy: Case report and review of the literature. Ultrasound Obstet Gynecol 1998;12:362-6.

45. Hepper PG, Shahidullah S. Trisomy 18: Behavioral and structural abnormalities. An ultrasonographic case study. Ultrasound Obstet Gynecol 1992;2:48-50. 